\title{
Value Configurations for Data and Connectivity Solutions in Digitalized Future Factories
}

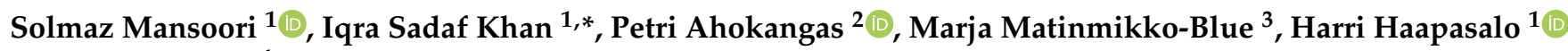 \\ and Seppo Yrjölä ${ }^{4}$ \\ 1 Industrial Engineering and Management (IEM), University of Oulu, FI-90014 Oulu, Finland; \\ solmaz.mansoori@oulu.fi (S.M.); Harri.Haapasalo@oulu.fi (H.H.) \\ 2 Martti Ahtisaari Institute (MAI), Oulu Business School (OBS), University of Oulu, FI-90014 Oulu, Finland; \\ Petri.Ahokangas@oulu.fi \\ 3 Centre for Wireless Communications (CWC), University of Oulu, FI-90014 Oulu, Finland; \\ marja.matinmikko@oulu.fi \\ 4 Nokia, FI-90620 Oulu, Finland; seppo.yrjola@nokia.com \\ * Correspondence: Iqra.Khan@oulu.fi
}

Citation: Mansoori, S.; Khan, I.S.; Ahokangas, P.; Matinmikko-Blue, M.; Haapasalo, H.; Yrjölä, S. Value Configurations for Data and Connectivity Solutions in Digitalized Future Factories. Processes 2021, 9 , 2233. https://doi.org/10.3390/ pr9122233

Academic Editor: José Barbosa

Received: 15 November 2021 Accepted: 9 December 2021 Published: 11 December 2021

Publisher's Note: MDPI stays neutral with regard to jurisdictional claims in published maps and institutional affiliations.

Copyright: (c) 2021 by the authors. Licensee MDPI, Basel, Switzerland. This article is an open access article distributed under the terms and conditions of the Creative Commons Attribution (CC BY) license (https:// creativecommons.org/licenses/by/ $4.0 /)$.

\begin{abstract}
The ongoing Industry 4.0 transformation places significant pressures on how businesses create and capture value. Technological advancements such as next-generation mobile communications are reshaping the business ecosystem of Industry 4.0, resulting in emerging business opportunities for new players, such as local operators, to collaborate and compete with mobile communications companies that are implementing I4.0. These changes raise the need to explore emerging business opportunities concerning the digitalization of future factories. New data and connectivity services are introduced to serve the needs of rapidly increasing machine-type communications that rely on connectivity, primarily through the fifth generation (5G) mobile solutions provided by local operators. Thus, this paper outlines the potential value configurations for data and connectivity solutions by identifying, matching, and bridging the utilizable resources and addressable needs within the factory processes. The research applies an exploratory approach and uses the Gioia method to analyze qualitative data of a single case. The study follows the connectivity-content-context-commerce typology (4C) of Internet business models to structure, analyze, and classify the identified needs and resources in future factories from the perspective of the local operator. The findings show that the content layer of $4 \mathrm{C}$ business model typology is the most dominant among data and connectivity-based needs and resources of future factories. The paper contributes by presenting four alternative value configurations for digitalization for local operators in the future factory context: the product, component, platform, and complementary businesses. The results suggest content- and context-specific businesses carries foremost business potential for local operators, however quantitative validation will bring fruitful research avenues. Multiple case studies and different data collection methods may also be considered in future studies.
\end{abstract}

Keywords: Industry 4.0; business ecosystem; value configuration; local operator; future factories; $5 \mathrm{G}$; digitalization

\section{Introduction}

The increased demand of integrating information and communication technologies (ICT) within manufacturing industry has paved the way for the fourth industrial revolution, commonly known as Industry 4.0 (I4.0) [1,2]. I4.0 denotes a recent automation and data exchange trend through novel technologies [3,4]. I4.0 is progressively transforming the manufacturing industry. Facilitated access to massive amounts of data, new technological developments, and a new wave of advanced analytical solutions as significant drivers of manufacturing transformation, improve process efficiency and economic outcome through quicker and better decision-making processes [5]. Considerable advancements in I4.0 
technologies, such as cyber-physical systems (CPS - the integration of computers, networks, and processes) and the Internet of Things (IoT-a system of inter-related physical objects), aiming at efficient data exchange force modern businesses to shift towards smart factories and adopt to the implementation of high-end technologies [6] that are expected to increase their competitiveness. Smart factories, also known as future factories, are defined as context-aware factories that assist people and machines in executing their tasks [7]. Connectivity plays a fundamental role in creating a context-aware factory, thus bringing the telecommunications industry into the I4.0 context. However, the capacities of the traditional $3 \mathrm{G}$ and $4 \mathrm{G}$ services that are provided by the mobile network operators are not enough to enable true I4.0. In the telecommunication industry, secure data exchange and transparent communication mainly comes from the implementation of advanced technologies such as the fifth generation of mobile networks (5G) which meet the requirements for massive and ultra-reliable machine-type communications [8] of future factories. As exponential traffic growth necessitates massive site densification, the current 4G technology is unable to keep up with ever-increasing traffic demand and is steadily deteriorating [9]. In terms of data rate, coverage, and reliability, $5 \mathrm{G}$ technology provides several advantages [10,11]. The 5G network infrastructure serves a key function for digital transformation and is paving the way for the exploitation of new business opportunities and the mitigation of entry barriers for new entrants to compete with existing players in the telecommunication business ecosystem [12].

One of the new entrants into the telecommunications ecosystem that is enabled by 5G is the local operator that helps to boost local service delivery [13]. Locally deployed $5 \mathrm{G}$ networks let various ecosystem stakeholders control their local networks and related activities and services [14]. However, new entrants face the challenges of how to successfully integrate product intelligence, innovation, and the coordination of products, services, and technologies [15] with other businesses. In this regard, few studies have addressed the question of potential business opportunities for local 5G network-based business ecosystems $[12,14,16]$, especially in I4.0 contexts.

Recently, researchers have addressed the question of how to integrate connectivity and data platforms in complex industrial ecosystems. However, the practical challenge in 5G business ecosystems remains regarding the role assessment of new entrants and their respective value propositions within spatially confined domains such as future factories [17]. Only a few studies have emphasized the changes in a new market segment for various stakeholders coming on by $5 \mathrm{G}[18,19]$, implying that further research is needed on the business opportunities for the different players in 5G networks ecosystem [20]. These results show that the current body of literature on emerging business opportunities for local 5G networks within the ecosystem is based on limited data [17]. Research on business model options for local 5G operators proposes vertical, horizontal, and oblique business models as generic 5G business models for local 5G operators [21]. The local operators' implementations are mainly investigated from the technical point with an emphasis on the blockchain platform [22], 5G access solutions [23], network functions and the operational units [24], and network slicing [25] and spectrum management [26] approaches. Therefore, the purpose of this paper is to illuminate this area and elucidate the emerging business prospects for locally deployed and operated 5G networks in the context of future factories.

First, we followed the resource configuration approach [27] to identify utilizable resources and addressable needs within the processes of future factories [27]. Second, we categorized the identified resources and needs into an Internet-based $4 \mathrm{C}$ business model (BM). The 4C business model typology assists business transition strategists in structuring various types of Internet-era business models, examining how and to what degree they create and capture value, and deciding whether they should be adapted. The typology presents four business models, each with its own set of value propositions comprising of connection, content, context, and commerce [28]. Since this research focuses on identifying alternative value configurations, the use of the BM approach will help to pinpoint value configurations between players' needs and existing resources in the business ecosystem. 
We follow this layered 4C typology of Internet BMs [29] that extends the Internet-based 4C business model [28], and particularly helps to structure, analyze, classify needs and resources, and analyze the extent to which novel value configurations can be created within an ecosystem.

The study aims to increase scientific knowledge and understanding of emerging business opportunities for local 5G operators in future factories context and in the implementation of potential value configurations for data and connectivity solutions. The research objective has been split into two research questions. The research questions first approach the problem first by identifying the utilizable resources and addressable needs within the factory processes (RQ1). The following research question explores the potential value configurations and business opportunities for data and connectivity solutions by matching and bridging the identified resources and needs in the context of the future factory (RQ2). The research questions are formulated as follows:

- $\quad$ RQ1: What are the main needs and resources that are related to the digitalization of manufacturing processes in the future factory context?

- $\quad$ RQ2: What are potential value configurations resulting from business opportunities for data and connectivity-based solutions in the future factory context?

The rest of the paper is organized as follows: Section 2 introduces a brief outline of future factory dynamics in the business ecosystem, including business model concepts and how local operators are framed. Section 3 presents the research design, including the data collection and description of the case that was used followed by data analyses. We then present our findings on the needs and resources that are related to manufacturing processes in future factories and potential value configurations in Section 4. Section 5 discusses the theoretical and managerial implications of the study, followed by limitations and future work directions. The study uses Appendices A and B to illustrate the key needs and resources, respectively, that are categorized based on $4 \mathrm{C}$ typology.

\section{Materials}

\subsection{Local $5 G$ Operators in the Factory of the Future}

The concept of Industry 4.0 refers to the fourth Industrial Revolution, which is based on the integration of production and business processes using information technology [30]. It has been identified as a key driver for deploying business model innovation strategies [31]. I4.0 can transform the way businesses create value by ensuring sustainable business performance [30]. The technological advancements comprising of sensors and data acquisition systems tackle the challenge of high-tech methodological implications and motivate smooth transitions towards smart factories that are needed for the future. [6,32]. Other upcoming trends such as mobility, security, and connectivity also contribute to the increasing need for smart factories in the future [33]. Moreover, due to the ever growing market demands and requirements that are related to agile responses, the smart factories require the adoption of high-end technologies to address many machine-type communication requirements [10].

The fifth generation of mobile communication networks (5G) can meet the connectivity needs of massive machine-type communications in future factories. The 5G network has become a decisive factor in the telecommunication industry because of its 'real-time and large traffic volume capabilities' [11]. The successful implementation of 5G can support a substantial digital revolution, which consists of finding and anticipating the core requirements of industry verticals [11] and the relevant trends of future factories. 5G has become an equally important topic for academics and industry practitioners during the last few years. For example, the $5 \mathrm{G}$ network, combined with modern technologies such as big data, the cloud, and edge computing, helps provide localized and reliable services for industrial ecosystems such as manufacturing plants [34]. In addition, 5G has the potential to enable end-to-end automation through the virtual deployment of manufacturing lines [35] and secure data transfer mechanisms within smart factories in combination with blockchain [36]. These developments have lowered the barriers that are related to market entry and have 
opened the way for new entrants which, in turn, has changed the operational ways of traditional wireless communication business ecosystem [12].

One of the new-entrant deployment models that is emerging through 5G developments in the telecommunication ecosystem is the local 5G operator concept [13]. This novel concept of local operators aims to open the telecommunication market for different stakeholders to deploy and operate their own local 5G networks to complement the dominant traditional mobile network operator (MNO) networks in local indoor settings. This study builds on the initial definition of the local operator concept as "an entity that combines connectivity with specific content services in spatially confined domains and depends on appropriate spectrum resources" [13]. Local operators may provide context-specific services and take on boosting local service distribution [13]. In the case of I4.0, local operators can provide local connectivity to inspire innovation as they can integrate novel, fast-deployable and cost-efficient solutions, match, and bridge new stakeholders' needs and resources, thus resulting in increased resilience. The local operator can be an independent and neutral body or act as a hybrid between MNOs and the local indoor environment, for instance, a factory. Local operators may own their infrastructure in a collaborative setting with other stakeholders within the ecosystem allowing them to serve respective local customers [13]. "Public, commercial, and industrial" sectors are highlighted in a study focusing on the possible scope of operation domains for emerging local operators in the indoor/small-cell 5G context [14]. Appropriate examples are hospitals and universities in the public domain, large-scale entertainment or sports venues, large shopping malls or retail chains in the commercial domain, and large-scale manufacturing and construction sites in the industrial domain [14].

\subsection{Business Models in Future Factories' Business Ecosystems}

Due to the spread of disruptive technologies, the functioning of business ecosystems in several industries has changed. Established businesses are forced to integrate their traditional business models with new digital business environments, resulting in business model changes and digital innovation [37]. As the cornerstone of digital transformation, the Internet impacted business ecosystems and business models. According to [38], Internet technologies enable the interconnection that is required to develop modern business ecosystems. While comparing the business ecosystem and an integrated value chain, the author suggests that information sharing will be a booster for customer focused value-creation in an internet-based business ecosystem. Implementing these contemporary internet-based technologies builds a connection between the ecosystem's players, their strategies, operations, and capabilities, profoundly reshaping businesses' competitive dynamics and operational interaction. In the context of the IoT, a business ecosystem is a complex network of connected stakeholders who may contribute to a business and co-evolve the ecosystem [39]. The IoT helps firms create new business models that are based on real-time data, improving the efficiency and effectiveness of decision-making processes [32].

$\mathrm{BM}$ as a focal gear can bridge technical advancement and economic value creation [40]. As a boundary-spanning unit of analysis [41-43], BM determines how a business creates and captures value [40,44-49]. BM is a way of doing business that aims to position themselves in the value chain to generate profits and advance themselves [50]. In today's market, a company's ability to adapt its business model to new business opportunities is critical to survival. Value logic is essential in developing innovative BM and necessitates systematic thinking [51]. Companies must constantly build and reinvent their business models to be competitive to produce and extract value from their business activities $[29,50]$. This continuous change implies a significant shift in the logic of value generation in the business models of suppliers and their partners [52].

According to [27], the methods for discovering and exploiting opportunities have changed significantly in the digital age as the scope of resources that a company can use to satisfy demands has expanded. Consequently, a business model must be configured in an ecosystem setting where businesses are linked and co-create and co-capture value through 
the utilization of resources [53]. The " $4 \mathrm{C}$ Typology of Internet BMs" proposed to analyze Internet-based BMs in a structured, easier way [28]. This typology includes four basic types of prototypical Internet BMs: connection, content, context, and commerce (4C). The connection BM adds value by supplying the physical and/or virtual network infrastructure that is required for information exchange over the Internet. The content BM provides convenient access to a wide range of online content. The context $\mathrm{BM}$ offers value by simplifying the structure. The commerce BM provides a cost-effective exchange environment for buyers and sellers of goods and services through initiating, negotiating, and/or fulfilling online transactions. Later, research broadened the concept and characterized it as a layer model within an ecosystem, where lower layers serve as enablers for upper layer BMs and each has its own value proposition that can be delivered separately or combined [29]. Service providers supply different connection technologies and solutions to link networks at the connection layer. The users' acquired data, information, and content are provided in the content layer.

\subsection{Value Configurations in the Business Ecosystem}

We can identify the value configurations that root the company to its respective business ecosystem underneath the business model level. The value configuration is defined by the company arranging its core activities to provide some value propositions. To comprehend and analyze the logic of value creation across a wide range of business contexts, three configurations, namely value chain, value shop, and value network attributing long linked, intensive technologies and mediating technologies, respectively, were presented as distinct generic value configuration models [54]. A value network further entails customers, places, and things as work nodes that facilitate different service exchanges between them representing internet businesses [55]. The interlinkage of these actors and functionalities regarding technical components develops value through products and services which leads to a value network configuration (VNC). [56]. In such a connected network of stakeholders, shifts in the dominating stakeholders' roles are unavoidable. Recent research proposed VNCs of 5G local area access for industrial machine-to-machine interactions at the connection level [57], concluding that the dominant players' roles will change and it is expected that the industry will depend on micro-operators for local area communication [57]. Identifying and categorizing a company's resources and needs in the business ecosystem can help understand the dynamic role of local operators. Thus, this research uses resource configuration prototypes [27] as sources of value creation in a digitally empowered environment (Figure 1).

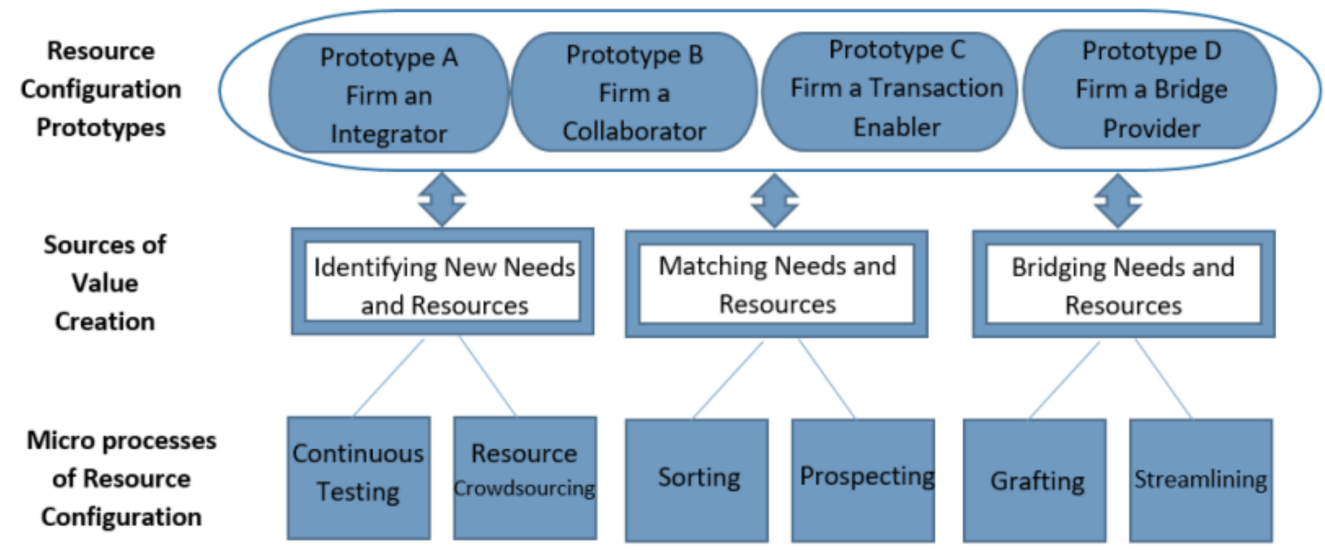

Figure 1. Resource configuration framework in a digitally enabled world. Adapted from [27], p. 239.

In this approach, four prototypes of resource configuration are proposed: the firm as an integrator, as a collaborator, as a transaction enabler, and as a bridge provider. "Identifying New Needs and Resources," "Matching Needs and Resources," and "Bridging Needs and Resources" are offered as means for value-creation that are facilitated by three sets 
of resource configuration microprocesses in this methodology [27]. "Continuous Testing" and "Resource Crowdsourcing" are micro-methods for discovering new demands and resources as ways for value-creation. Continuous testing is an iterative method of adjusting a firm's offerings according to their value co-creators' changing and unattained demands through rapid feedback loops between the firm and respective co-creators. Such continual improvement advances a company's efficiency in identifying unmet needs and the value creation potential of a resource arrangement. Resource crowdsourcing is an approach to problem-solving which improves a company's capacity to discover and exploit underutilized resources as the number of underutilized sources constantly increases in the digital era [27]. "Sorting" and "Prospecting" are micro-processes that fall under the "Matching Needs and Resources" value creation basis. The sorting process entails developing and implementing strategies for classifying both resources and the needs of transaction parts. Due to the dynamic nature of the data, an iterative process should be adopted to provide a well-organized match between needs and resources. Subsequent processes have focused on assessing past and current data to prospect future demands and resources [27]. "Bridging Needs and Resources" is achieved by "Grafting" and "Streamlining" resource configuration micro-processes. Notably, the primary focus of these procedures is the customer's role in the digital era. In addition, to produce value in this type, the focal firm utilizes the distinguished characteristics of related co-creators. The first step of micro-processing is "grafting", in which the focal firm attempts to combine the previously unconnected and independent needs and resources. It raises configuration value by bringing unique complementarity between resources and needs. This approach necessitates creativity and the capacity to attain quick and broad access to resources. The innovative connections that are created through the grafting procedure are then improved in "Streamlining" by offering additional resource connections [27]. The proposed resource configuration prototypes show how value is created in digitally enabled business ecosystems, which is in line with the scope of the current study. Therefore, we use the same value logic to investigate potential business opportunities for new local entrants (local 5G operators) and their corresponding roles for value propositions within future factories.

\section{Research Methodology}

This study follows an inductive reasoning approach that is often applied in exploratory research $[58,59]$. The study can be categorized as representing exploratory research since there are limited studies and knowledge about the phenomena and targeted sector that are under examination. The qualitative reasoning approach is used as a research strategy. Inductive studies and qualitative research are frequently linked and have a great deal in common since both "provide insights for the generation of theoretical frameworks" [60]. The single case study is used as a framework for data collection and analysis. Despite its numerous advantages, qualitative research has been criticized for failing to support its stated conclusions properly [61]. It is assumed that a systematic strategy to support adequate findings is often lacking in qualitative research. This study applies the Gioia method that is often used as a systematic approach for conducting rigorous research. [61]. The Gioia method analyzes a phenomenon via an interpretative perspective. The collected data is categorized and analyzed at three levels of abstraction in this method: first-order concepts, second-order themes, and aggregate dimensions. The term "first-order concept" refers to early conceptions that are derived from the data and classified based on similarities. Then, by grouping similar categories, "second order themes" are established, and then following level of abstraction, "aggregate dimensions," are built by merging the second order themes [61]. As both inductive reasoning and qualitative research seek to propose new concepts that are based on observations, it is logical to use the Gioia method as a systemic strategy and analytical logic to link data to propositions and produce new persuasive conclusions. 


\subsection{Case Study}

The case company is an electronic manufacturing factory in Finland that operates in the ICT industry with over 30 production sites worldwide. The production line is equipped with multiple sensors and utilizes a 5G network. The case company focuses on automation based on IoT, cloud solutions, and 5G to gain profitability, value, and efficiency and provide innovative solutions. This automation needs a reliable and consistent wireless connection to cover robots, sensors, and machines. Our case provides a reliable illustration for this research because it holds a pioneering position to test and apply I4.0-based technologies that cover multiple use cases in the telecommunication industry and intends to transform their traditional production operations to unique ways of value-creation using data.

\subsection{Data Collection and Analysis}

This study is part of a multidisciplinary research project focusing on providing local, high-quality, wireless services to meet the case-specific needs of various vertical sectors in the telecommunication business ecosystem. In this study, the primary data was collected from a focus group discussion [62] during a full-day micro-operator factory workshop that was attended by four project researchers, five factory specialists, and the factory's head of the research strategy department. The number of participants was ten, which appears to be an appropriate sample size for a focus group discussion. Several meetings were held prior to the workshop to discuss this study's aim and to define the workshop program with project participants. The focus group discussion was conducted in the workshop to gather participants' opinions on the defined aims of the research and the workshop's focus was on the current and future requirements of manufacturing processes concerning connectivity and data-related issues. The discussion was facilitated by one of the skilled researchers who led the discussion. Transcriptions of the participants' presentations, discussions, and suggestions were used as a primary data source. In addition to the workshop records, the researchers strived to gather secondary data from various sources, such as the multidisciplinary research project and company documents, to supplement the primary data.

For the data analysis, we divided the acquired information into two categories: case factory needs and case factory resources. Quotations of both needs and resources were coded and classified according to their relevance with the $4 \mathrm{C}$, BMs. The data were analyzed using three consequential processes of Gioia's systematic procedure. Firstly, the records of the workshop were transcribed and analyzed to form various categories reflecting on the differences and similarities between quotations. Subsequently, the categories that were identified were given descriptions (labeling) that build "first-order concepts" of data structure. Figure 2 depicts the three sequential steps of the Gioia approach and shows the data structure, explaining how the collected data was analyzed in this study. Multiple interpretations were possible due to the overlapping statements in the data analysis. For instance, the statement "the case company is in search of extract value from (underutilized) data" could be ascribed to content as well as commerce-related needs. In another quotation, for example, the quotation "need for sharing real-time transactional data through web services instead of a per-day update" could be compressed into the needs of the case company, related to real-time data. Next, the identified categories were labelled with phrase descriptions which produced the first-order concepts. Second-order themes were explored next, emphasizing the novel notions that have fewer references in the previous literature. The question that was related to the credibility of the second-order themes is whether they could offer ideas that can help us define the phenomenon we were investigating was answered during this process. After this step, the groups of quotes were coded with appropriate labels for all of the sub-set concepts. The labels were used as emerging themes in the Gioia method's second process. In this study, after the classification of connection, content, context, and commerce-related needs and resources, a color code was given to each quotation to clarify to which of the $4 \mathrm{C}$ layers it belonged. Finally, aggregate dimensions that were based on second-order theme connections were created 
to construct broader categories that aggregated similar concepts or thoughts [61]. Then, the aggregate dimensions of the data structure were utilized to discover potential business prospects for local operators. This process is based on [27] business model prototypes, which use a value creation-centric approach to identify potential business opportunities and associated value configuration in future factories. The value configuration models include needs (N), resources (R), and value co-creators (VCC) as players within the future factory business ecosystem.

\begin{tabular}{|l|c|}
\hline \multicolumn{1}{|c|}{ First-order concept } & Second-order theme \\
\hline Concept 1 & Theme 1 \\
Concept 2 \\
Concept $\mathrm{n}$ \\
\hline $\begin{array}{l}\text { Concept } 1 \\
\text { Concept } 2 \\
\text { Concept } \mathrm{n}\end{array}$ \\
$\begin{array}{l}\text { Concept } 1 \\
\text { Concept } 2 \\
\text { Concept } \mathrm{n}\end{array}$ & Theme 2 \\
\hline
\end{tabular}

Figure 2. The structure of data used.

\section{Results}

\subsection{Identified Needs and Resources}

The search was initiated by pinpointing the usable resources and achievable needs that were confined in future factories [27]. A total of 11 themes emerged as needs and resources, of which seven were common to both themes. Even if 7 of the 11 developing themes have the same labeling terminology, this does not mean that they are equivalent. They are about the same themes, but they are founded on distinct first-order conceptions. In the appendices, the data structure for both needs and resources highlights the basic concepts of each theme in identifying both needs and resources. After applying the Gioia approach to the list of needs and resources, 11 s-order themes emerged, as follows:

1. Internal data access emerged as both a need and a resource of future factories. On the needs side, the case factory wondered about restricted access to internal data from different segments. At the same time, from a resource perspective, sources mentioned that there is an extensive amount of data that is generated by various devices and sensors around the production line that could be utilized appropriately.

2. In the high-quality connection and content-specific service theme, experts discussed future factory needs, emphasizing the importance of reliable connections and local specific demands for the communication of numerous wired and wireless devices, robots, and components on the factory floor. As the case company is empowered by $5 \mathrm{G}$ and IoT technologies, this theme shows considerable potential for high-quality connection and content-specific services from a resource point of view.

3. Communication and data exchange reflected the importance of data exchange and the communication of different segments and stakeholders to meet existing and future demands of various segments from the standpoint of the case company's needs. However, the case company's willingness to communicate, exchange data, and improve the information flow (resource) between players shows that many underutilized resources can be used based on sharing economy principles.

4. External data access showed the company's awareness about valuable data, which is in control of third parties. It is undeniable that third parties need access to some data from communication with other players in the ecosystem that could be vital for the case company. Therefore, access to external data is explicitly mentioned as needed by experts. Furthermore, the case company includes some machines, robots, and services that are provided and controlled by third parties. Therefore, the 
extensive data gathered by such devices inside the factory floor could be considered an underutilized resource for the case company.

5. Data ownership is close to the concept of external and internal access to data. Data is "owned" by different managers of different segments separately within the case company, so data management needs to be organized. However, there are large amounts of data as resources which are not managed because of different owners in different segments. Therefore, the integration between data owners could meet the company's needs with existing resources.

6. Data governance is identified as the need to process, simplify, and manage extensive data flow. Data is mainly stored in distinct segments that are not usable by other parts' users before being processed. Conversely, the case company has an adequate reporting system and applies middleware in some parts as resources that need to be processed and managed.

7. Extracting value from data is rooted in the case company's logic on novel ideas about value creation from invaluable underutilized data. There was considerable discussion about numerous databases, including various data types as resources, which can be turned into usable forms. The factory experts emphasized that the case company is finding ways to extract value from underused data and filling the gap in data utilization in the best possible way.

8. Spatial/tailored content requirements were identified as needs. Factory experts' apparent demand and specific requirements for tailored content showed great potential for service providers in the ecosystem to meet those spatial/tailored content requirements and grow in the field.

9. Data quality emphasized the decisive role of reliable and real-time data to meet the current needs of the case factory.

10. Value co-creation was identified as a resource because the case company's strategies for value co-creation can enhance the chances of collaborations in the ecosystem for other players like local operators.

11. Integration requirements emerged as a resource because the case company is testing more integrated manufacturing lines that call for new services and businesses to support the integration.

The data structure of a future factory's needs and resources is illustrated in the end of this section.

\subsection{C Business Models}

The identified resources and needs were next categorized into a $4 \mathrm{C}$ layered Internetbased business model (BM) comprising connection (C1), content (C2), context (C3), and commerce (C4). The $4 \mathrm{C}$ classification for identified needs and resources is stated in detail (see Appendix A). On the needs side, there have been requirements for high-quality connection and network infrastructure services to increase user interconnectedness and fulfill mobility requirements. Connection BMs, which provide Internet communication services [28], can meet these demands. Therefore, the need for high-quality connection and content-specific service themes is categorized in connection BMs in line with the responses of the workshop participants, such as "There is a need for wireless connection inside a factory to meet sensors, robots, and mobility requirements". The focus of business at the content layer is on the collection, selection, compilation, and transmission of online content to enable simple, user-friendly access to various relevant content [28]. The results showed that content BM is the dominant concern of future factories. For example, the case company highlighted a significant concern about the efficient exchange and management of large amounts of data to extract value from them in collaboration with third parties. This collaboration calls for integrated systems and processes enabling value co-creation within the future factories. To that purpose, they utilize several systems to assist with the effective exchange and management of large amounts of data. However, they still need to harmonize the synthesized data and systems properly. This conclusion is drawn from 
the subjects' responses, such as "We have a lack of traceability and a lot of work at the moment and how we could beat by using mobile or network" and "We hope to enable some future use cases such as further analytics, machine learning, and AI solutions. We want to extract value, so storing the data is not point, we have some business targets, we are not just doing study".

The third layer, context BMs, provides structure and navigation for online users, increasing the transparency of existing online data in a specific context [28]. In this type of business, the need for high-quality connection and context-specific services in different places was identified from the responses, such as "If you have 1000 employees and you connect each of them with some wearable so on, then you start to have lots of mobile types of needs" and "If a connection is not working, that location loses capacity, basically". On the other hand, existing equipment and capabilities regarding communication and data exchange facilitate the use of context-specific, underutilized data, which were categorized as resources from the data: "In sub-floor layer devices, clients and end users are creating data". The final commerce layer of 4C BMs refers to the ability to commercialize any or all of the connection, content, or context-specific resources, actors, or activities that are associated with ongoing communications [14]. The findings show that most of the needs that are mentioned in content BMs have been repeated here, with a higher focus on the importance of information transition and extracting value from data through external data access. For example, "Combining relevant data in structured way, we hope to enable some future use cases such as further analytics, machine learning, and AI solutions. We want to extract value, so storing the data is not point; we have some business targets, we are not just doing study" and "We need to get all the data from a third party (third parties say some parts of processes are not necessary for your company)".

Since the focus of the current research is identifying alternative value configurations, the BM approach will pinpoint value connotations among players' needs and available resources within the business ecosystem.

\subsection{Alternative Value Configurations for Local Operators}

In response to the second research question, the aggregate dimensions from related concepts within the second-order theme were extracted in search of potential business opportunities and value configuration for local operators in a future factory context. As a result, based on the value configuration prototypes in the digital era [27], the recognized needs and resources are investigated to determine the emerging business opportunities for local operators in the future factory context.

\subsubsection{Product Business}

The first identified business opportunity is called "Product Business". According to our data, when the emphasis on recognized needs and resources is mainly internal and restricted to the connection layer of $4 \mathrm{C}$ businesses, the case factory operates on the most traditional business models in a conservative mode by seeing the opportunity to sell a product. Thus, in cases of tightly coupled relationship between needs and resources, the presiding instinct in future factories is to address needs for collaborating with a particular operator; the local operator can function as a local turnkey and single-point solution provider. Because product business depicts the most basic method of value creation in the digital age [27], the finding supports the notion that although it works, this type is the least suitable role for local operators in the future factory context (see Figure 3) due to a minimal emphasis on expanding the business despite the available potential. 


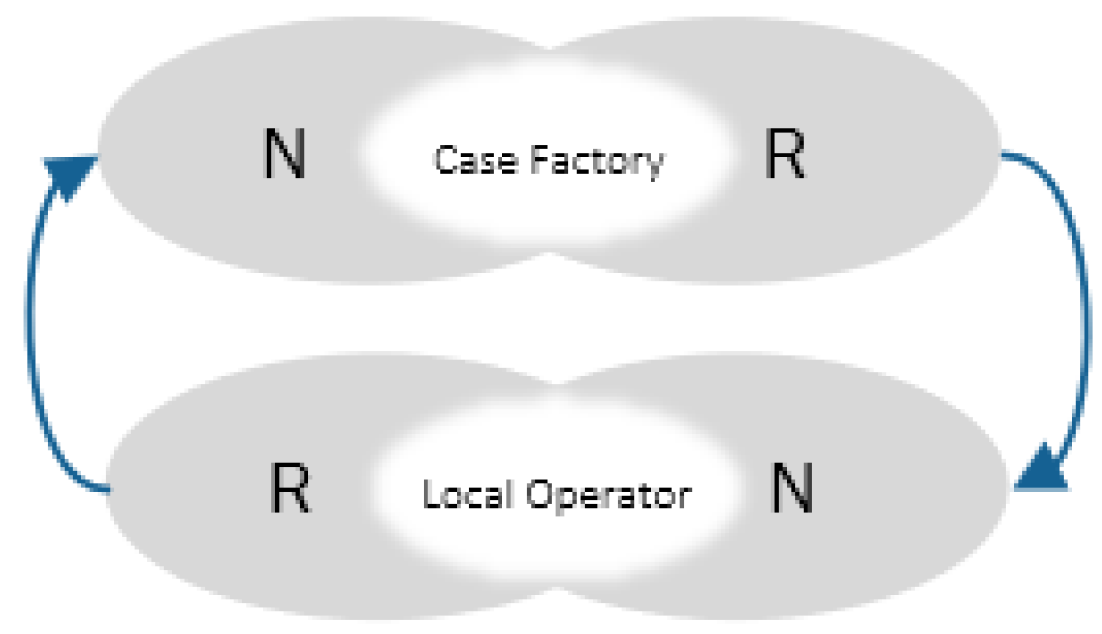

Figure 3. Local operator as a product business.

\subsubsection{Component Business}

The second business opportunity, "Component Business", resembles the first opportunity but with a greater focus on data exchange and communications. In this type of business opportunity (Figure 4), the needs and resources are closely connected, rising from different sources; the local operator serves the needs of the case company as a "bit pipe" and a local 5G socket through collaboration with other partners. Additional business can then be created to complement the component business.

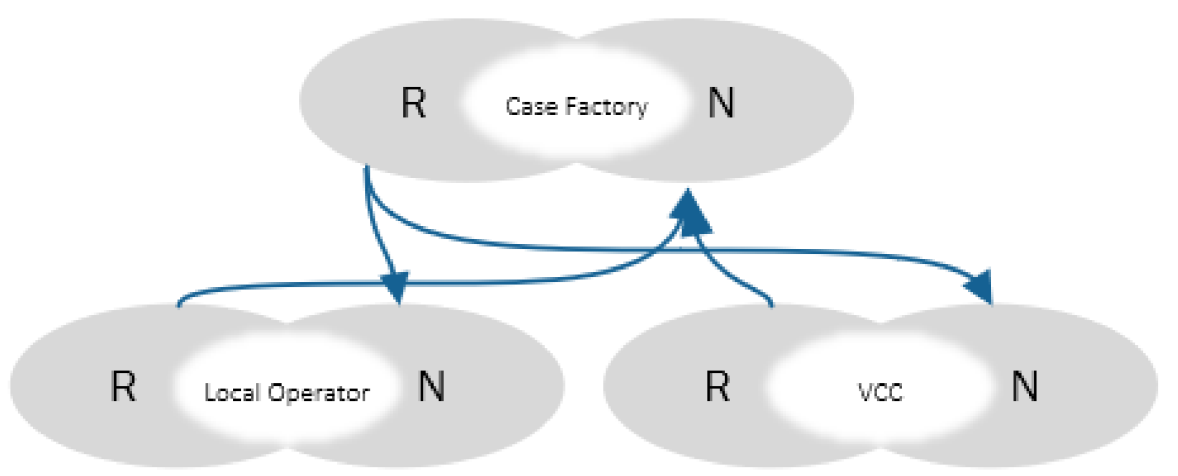

Figure 4. Local operator as a component business.

\subsubsection{Platform Business}

The most potential that new business opportunity recognized for local $5 \mathrm{G}$ operators in the context of future factories is the "Platform Business", which emphasizes permissions that are related to external data, data exchange, and data quality. In this type of business (Figure 5), the local operator can serve as a platform to communicate and exchange data between VCCs in a multi-sided marketplace, serving several types of stakeholders with different offerings. One value co-creator (VCC) needs something in this scenario, and another VCC supplies something. The local operator performs a key role in bringing the two sides together and assisting with harmonizing and managing this process. Findings show that a substantial number of needs and resources are characterized by this type of business opportunity for local operators. This characterization hearkens back to the statement [27] that businesses are increasingly embracing this type of value configuration in the digital age. It is the most appropriate value configuration for local operators and it is the basic underlying business model of the local operator in the future factory context. 


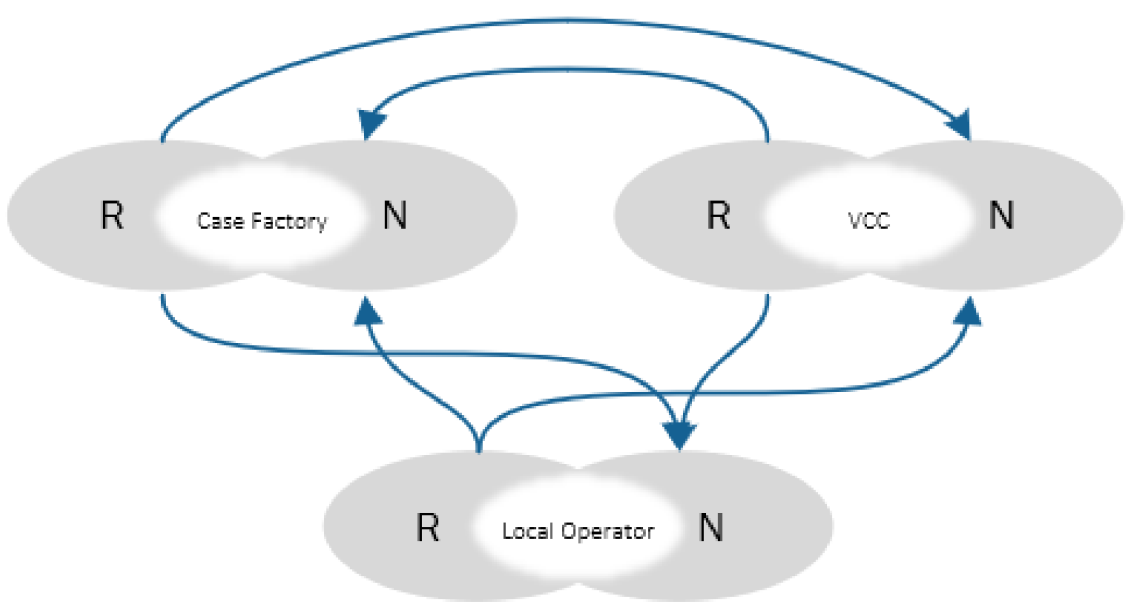

Figure 5. Local operator as a platform business.

\subsubsection{Complementary Business}

The final emerging business opportunity for local operators is titled "Complementary Business", which characterizes it as more outward oriented. This type of business enables making money from other businesses and requires collaboration with firms in different markets to experience different types of monetization (Figure 6). The resources and needs are coupled (more) by outsider players in the ecosystem without direct care for the type of needs and resources. The complementary business appears non-existent or only possible in close collaboration with the dominant players such as ERP (enterprise resource planning) and SAP service providers. As a result, local operators might serve as a generic platform, similar to what Google is already doing in the industrial realm.

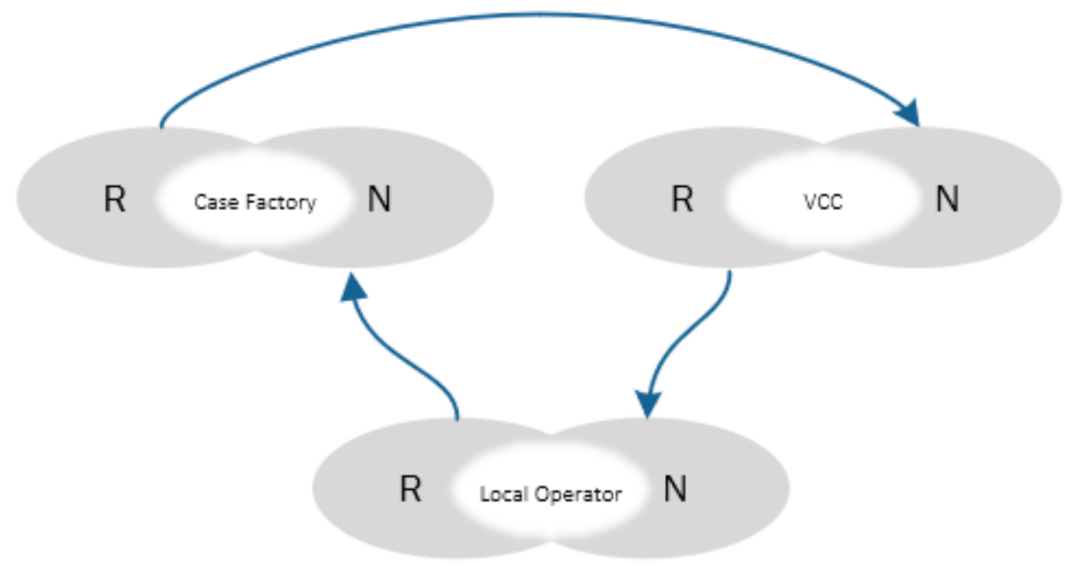

Figure 6. Local operator as a complementary business.

The summary of the data structure of a future factory's needs and resources and the corresponding business opportunities for local operators are depicted in Figures 7 and 8 , respectively. These figures show a comprehensive summary of the collected and analyzed data following the study's objectives. The figures represent the current state of future factory needs and resources, forming the basis for local businesses operators to realize potential business opportunities that are emerging in the business ecosystem. 


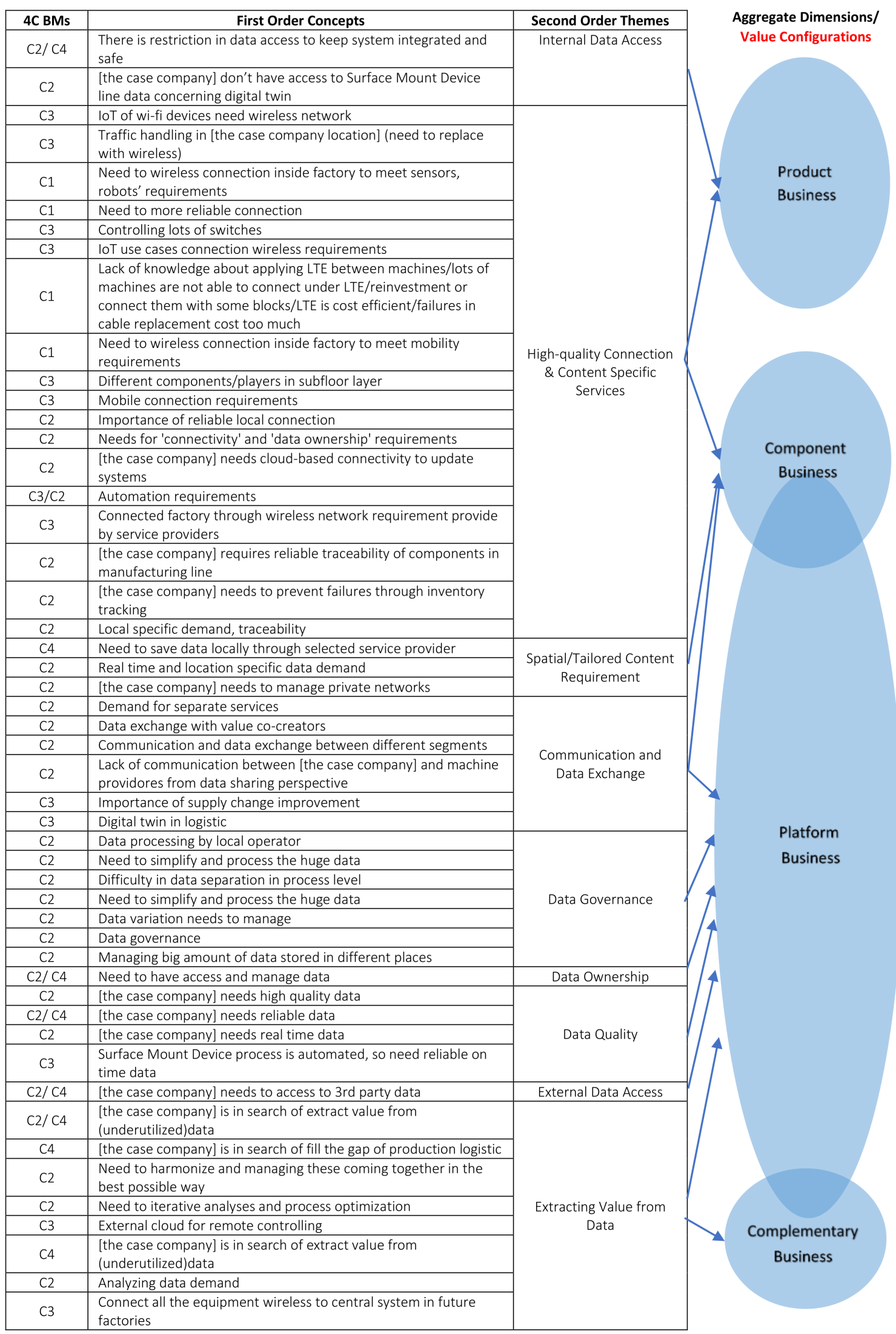

Figure 7. Summary of the structure of data used in future factory as needs. 


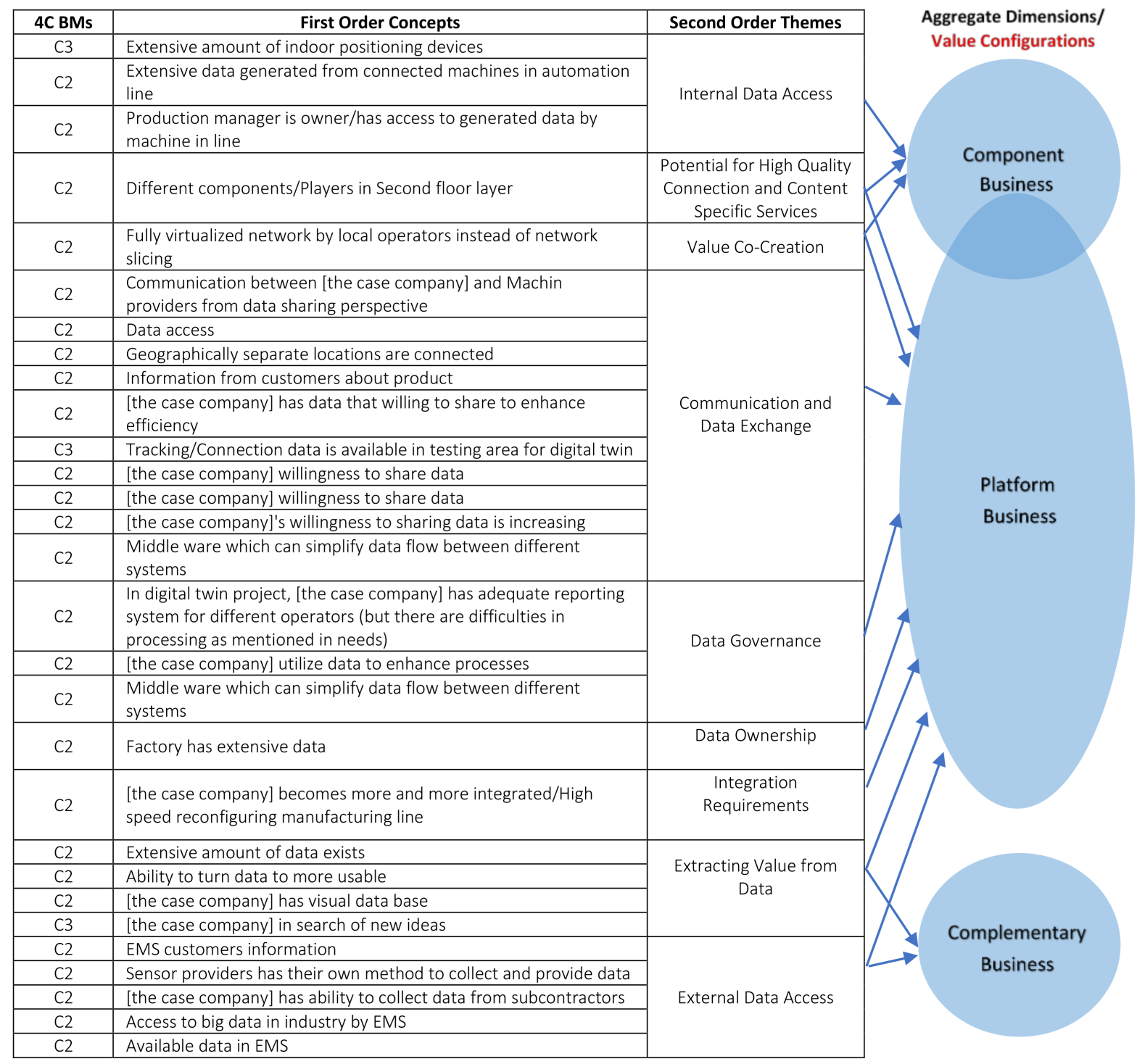

Figure 8. Summary of the structure of data used in future factory as resources.

\section{Discussion}

This study analyzed the addressable needs and accessible resources of a case company to assess local operators' role and value proposition of local operators in future factories. The research revealed 11 themes for needs and resources. These topics mostly concerned how to access and communicate data in a trustworthy and high-quality manner and how to create value from data in collaboration with others. The findings emphasized the importance of data quality and accessibility, as well as data sharing and governance mechanisms, as the most serious challenges for future factories. This finding confirms that the adoption of information sharing in digitally enabled business platforms is heavily influenced by data quality and trust [63]. The finding also provides additional support for [10] and [64], who argue that a combination of technologies such as $5 \mathrm{G}$ and IoT can satisfy the requirements of connected devices, information, and humans in I4.0. The advantages of openness in the platform ecosystem that concern data sharing and governance procedures reflect the strategic threat that new entrants pose to established resource platforms. This is in line with the claim that the more openly and widely a platform's resources are made available to third parties, the more vulnerable the dominant platform player may become for new entrants' exploitation [65]. Moreover, the case company shows the ability to tackle future concerns by increasingly integrating machines in geographically dispersed locations. The 
findings confirm that rather than being stored in silos, the massive amount of data as a resource can be digitalized and exchanged via integrated systems [66]. Nevertheless, the case company shows potential for novel and emerging business opportunities in the data-driven business ecosystem from a resource standpoint.

To assess the role of local operators in the context of future factories, the identified needs and resources were analyzed based on resource configuration prototypes in the digital age [27] and the 4C BMs [28]. The proposed alternative business opportunities for local operators demonstrated multiple means to create value for all players which might be used in different ways depending on the circumstances. For instance, the connection layer acts as a foundation for higher layer businesses to create value. The connectivity layer had been an issue in the early stages of digital transformation for the case factory. However, the findings showed that their concerns have grown for the content layer matters that comprised of the demands and resources and implied the availability of digital content that might be used to meet content-related needs [29].

The data shows that the emerging needs and resources could be addressed and used optimally by local operators within the platform configuration. Value is derived when a business acts as a platform, supplying resources to facilitate transactions between two groups of value creators whose needs can be met by the resources of the other group. This role qualifies local operators to operate in data platform businesses and use new value creation and value capture approaches $[37,67]$ as business platforms are a growing trend in the digitalization era. This further implies that, in practice, the business ecosystem is occupied by a wide range of users with increasingly more complex and overlapping value configurations. This is in line with the significance of constantly evolving ecosystems in terms of operational domains, resources, and the dynamics between actors and their roles in the broader ecosystem [42]. The data also indicates that various players can take different roles and value configurations to use accessible resources to address needs. In addition, the role of a local operator is not actor-dependent; the role could be undertaken by a range of players within the business ecosystem, including content providers, facility owners, and device and equipment vendors. This argument is in line with the findings of [68] that a service provider, machine manufacturer, network equipment vendor, venue owner, or the factory itself, can all take on the local network operation role.

The findings imply that the platform business is the most probable business opportunity for local operators is the platform business. It is expected that local operators can carry out their duties in more flexible ways than the four distinct proposed business models and value configurations at the top of the framework and the scope of the identified business opportunities might fall somewhere between these district categories. It is further suggested that alternative scenarios and business models unfold to different value configurations that enable successful digitalization. This correlates fairly well with [27] and further supports the notion that a combination of prototypes can bring multiple opportunities for value creation [27]. We suggest one such possibility for local operators (Figure 9) below. The mixed type of business for local 5G operators shows the necessity of openness in adopting options. Local operators must carefully choose and assess alternative data and connectivity solutions to determine which option best suits their customers' purposes.

In this mixed type of business, the local operator plays a role in the product business and platform business juncture. Even though most needs and resources are correlated to platform businesses, more traditional business models still exist in the business ecosystem. This value configuration enables local operators to collaborate with a wide range of value co-creators, from traditional fragmented to platform-based integrated business domains. The local operator uses its internal resources to address the needs of the case factory and other value co-creators. Conversely, the needs of local operators could be addressed via resources under the control of the case factory and other value co-creators within the ecosystem. Furthermore, if external information platforms, such as ERP service providers, a local operator could strengthen its position in creating and capturing value in a novel way within the ecosystem. A local operator's value creation capabilities within the business 
ecosystem may be boosted due to having greater access to resources to fulfill significant requirements of its own and those of other value co-creators in the business ecosystem. This was proposed as an example to indicate that there are many alternative ways that a local can create value by minimizing the asymmetry of underutilized, unstructured data from both needs and resources. Structured data increases the probability of prospecting participants' needs in a fragmented ecosystem, which might be a considerable business opportunity for local operators.

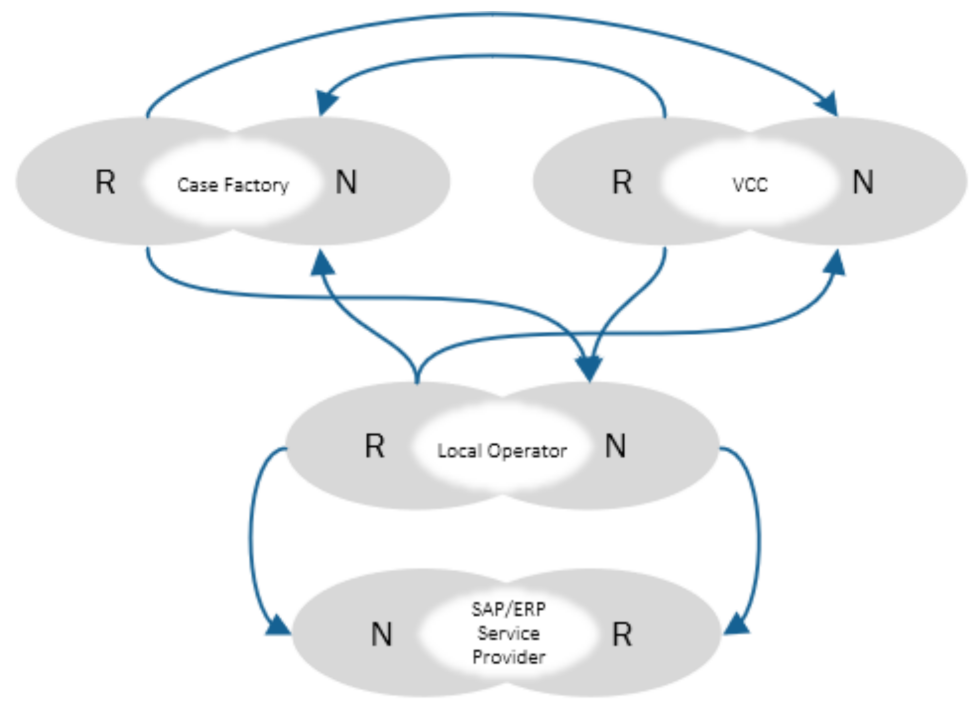

Figure 9. Mixed type of business for local operators.

Following up on the study findings that are presented in the previous section, we have developed a new combination of business model configurations for digitalized future factories. Assessing the role of local operators in the digital age based on 4C BMs [28] allows us to refine and empirically and conceptually validate the resource configuration-based theoretical framework [27]. Empirically, the modified framework (Figure 10) illustrates alternative value configurations with corresponding needs and resources that are based on $4 \mathrm{C}$ BMs. From a business ecosystem perspective, the framework emphasizes the importance of value logic in the development of innovative BM as well as the need for systematic thinking when establishing potential business opportunities for digitalized future factories, taking into account the needs and resources of all value co-creators in an ecosystem setting [51,52]. Conceptually, value can be created and captured in a novel way by matching and bridging a future factory's identified needs and resources. This provides a basis for the developed framework (Figure 10), which is built upon resource configuration framework and logic of value creation in the digital age, as presented by [27]. From the BM perspective, this framework gives a clear idea about how the $4 \mathrm{C}$ BMs may be exploited to cooperate [28] and support each other [29] in the value creation of an ecosystem to allow value capture from potential business opportunities. There is a clear fit between digitalization-driven business opportunities and the identified needs and resources, as the majority of the needs and resources are related to the platform and complementary business opportunities. The $4 \mathrm{C}$ BM analysis of identified needs and resources reveals that the most addressable needs and underutilized resources are grouped in content and context BMs. In other words, content- and context-related businesses are primary business fields for the case company. This result has been depicted at the top of the value creation sources in the framework to present a comparative picture of needs and resources in the case company and a solid foundation for possible business opportunities for local operators in digitalized future factories. In short, the possible emerging business opportunities revolve around collaborative business models that are linked to the future factories' content- and context-related needs and resources. 


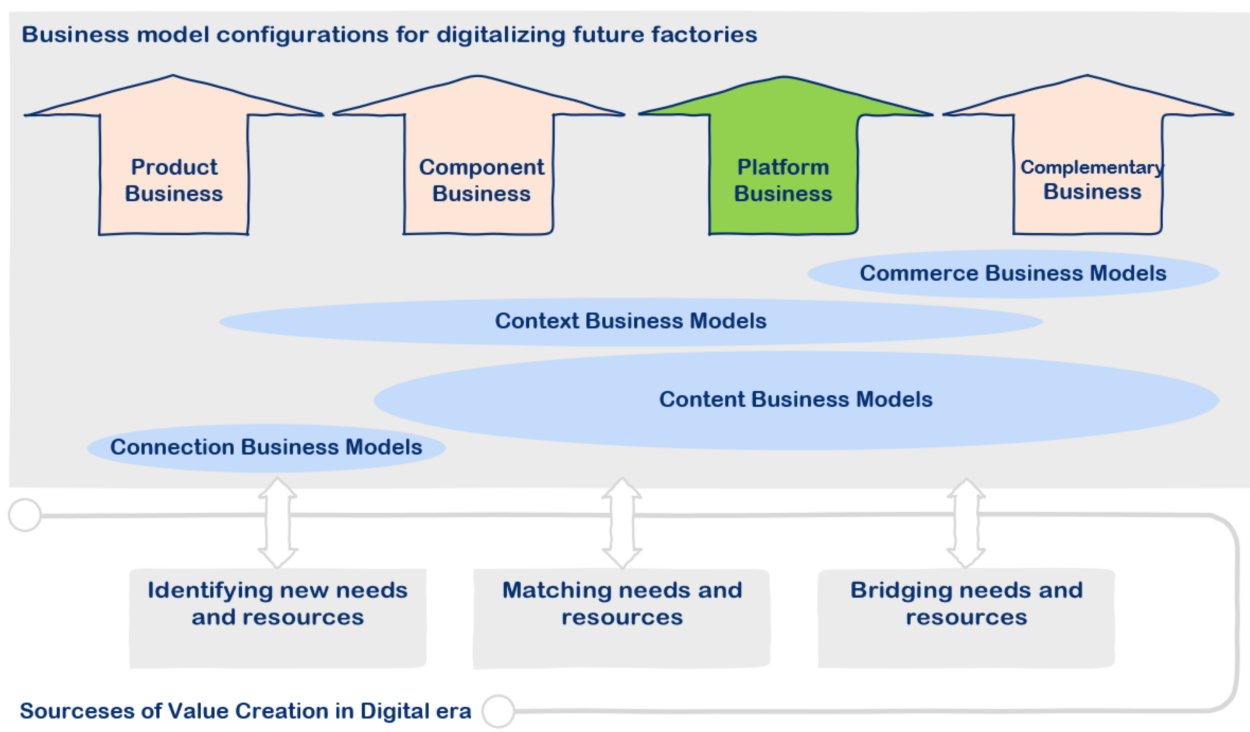

Figure 10. Business model configurations for digitalized future factories.

\section{Conclusions}

Industrial verticals have been envisioned to become one of the most lucrative business opportunities for $5 \mathrm{G}$ technology providers, local operators, and I4.0 service providers and users alike. However, alternative value configurations and potential business opportunities with business models for local 5G operators have remained a rarely investigated research topic. In this domain, this paper adds value to the research on alternative value configurations for digitalization within the future factory context with theoretical contributions and managerial implications.

\subsection{Theoretical Contributions}

Extending on [21,28] and [29], this paper presented detailed I4.0 business model configurations for local operators and contributed to scientific knowledge regarding our understanding of resource configuration literature, adding the $4 \mathrm{C}$ internet BMs [28] dimension to theoretical resource configuration framework [27] in a digitally enabled world. The paper presented four alternative value configurations [21] for local operators in a future factory context. In addition, this paper increased understanding of how the I.40 ecosystem [20] may be revitalized with advanced connectivity solutions. By assessing the role of local operators in future factory contexts that are based on 4C internet BMs [28], this research also extended the context of the 5G business ecosystem. Finally, this paper contributed to an ecosystem view in which the business opportunities are determined by the ecosystem members' complementarity potential based on their offerings.

\subsection{Managerial Implications}

From the managerial perspective, the findings of this study can be utilized broadly by managers that are working in industrial verticals searching for novel ways to create value in digital businesses. The results show how the local operator concept exhibits competitive advantages in the I4.0 context and applicability in all industrial segments moving toward future factories. Our findings pinpoint functional areas of considerable business opportunities for local operators to serve industrial verticals with connection, content, context, and commerce-related services. Although the focus of this study is local operators, the role of local operators is stakeholder-independent. It could be undertaken by a broad group of players, including service providers, facility owners, devices, equipment vendors, and the dominant mobile network operators themselves. In addition, the findings that are related to BM layering will help managers to measure the positioning of their BM regarding the factory's transformation according to future needs. 


\subsection{Limitations and Suggestions for Future Research}

Limitations that are related to the empirical and theoretical scope and approach and methodological choices are an inseparable part of any research, and this study is no exception. As our future factory case dealt mainly with manufacturing operation processes from data and connectivity perspectives, other factory-level macro- and micro-processes such as warehouse operation and maintenance were outside the scope of this research. Future research is suggested to analyze the needs, resources, and value configurations also on the areas that fall outside the scope of this research. This research also applied the business model concept with a specific focus on local operators. Future research could also extend the analysis to examine whether mobile network operators' I4.0-related opportunities and business models of mobile network operators differ from local operators.

Our choice of methodology also restricts the generalizability of the results. This study applies qualitative analysis principles to data from a single case factory; further studies are suggested to validate the findings with quantitative approaches and compare the results with other factories. Lastly, the results suggest that content- and contextrelated platform businesses are the most often anticipated business opportunities for local operators. However, quantitative validation is needed to clarify the potential business opportunities in these areas [69].

As a forward-looking conceptual extension, we suggest researchers focus on the fifth C [69], computation, business models in the context of future factories and I4.0. As the 5G technology continues to grow with its increasing capability of virtualized performance, carrying the potential for the next industrial revolution [70], it will be essential to assess and evaluate the computation-related security measures and artificial intelligence performance incessantly. More research about $5 \mathrm{G}$ best practices in manufacturing units covering endto-end security architecture including network, equipment, and applications is, therefore, needed [71].

Author Contributions: Conceptualization and supervision, P.A., M.M.-B. and H.H.; writing-original draft, preparation, methodology, writing - review and editing, S.M.; writing, reviewing, and editing I.S.K. and P.A.; and validation, P.A., M.M.-B. and S.Y. All authors have read and agreed to the published version of the manuscript.

Funding: Authors would like to acknowledge the funding for APC from Business Finland in 5GVIIMA project and Academy of Finland in 6G Flagship (grant 318927).

Informed Consent Statement: Informed consent was obtained from all subjects involved in the study.

Data Availability Statement: The data presented in this study are available as supplementary material in Appendices A and B.

Conflicts of Interest: The authors declare no conflict of interest.

Appendix A. Structure of Future Factory Needs Based on 4C

\begin{tabular}{|c|c|c|}
\hline 4C BMs & First-order concept & Second-order theme \\
\hline \multirow{4}{*}{ 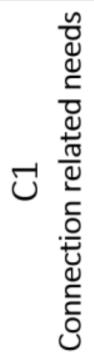 } & $\begin{array}{l}\text { Need to wireless connection inside factory to meet sensors, } \\
\text { robots' requirements }\end{array}$ & \multirow{4}{*}{$\begin{array}{l}\text { High quality connection \& content } \\
\text { specific services }\end{array}$} \\
\hline & Need to more reliable connection & \\
\hline & $\begin{array}{l}\text { Lack of knowledge about applying LTE between } \\
\text { machines/Lots of machines are not able to connect under } \\
\text { LTE/reinvestment or connect them with some blocks/LTE is } \\
\text { cost efficient/Failures in Cable replacement cost too much }\end{array}$ & \\
\hline & $\begin{array}{l}\text { Need to wireless connection inside factory to meet mobility } \\
\text { requirements }\end{array}$ & \\
\hline
\end{tabular}

Figure A1. Connection-Related Needs. 


\begin{tabular}{|c|c|c|}
\hline 4C BMs & First-order concept & Second-order theme \\
\hline \multirow{32}{*}{ 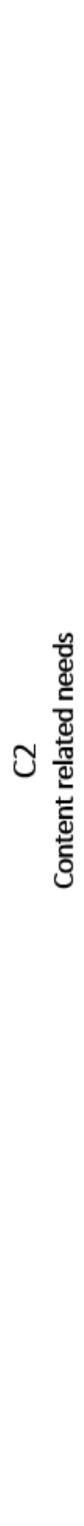 } & Demand for separate services & \multirow{4}{*}{$\begin{array}{l}\text { Communication \& Data } \\
\text { Exchange/Sharing }\end{array}$} \\
\hline & Data exchange with value co-creators & \\
\hline & $\begin{array}{l}\text { Communication and data exchange between different } \\
\text { segments }\end{array}$ & \\
\hline & $\begin{array}{l}\text { Lack of communication between the case company and } \\
\text { machine providores from data sharing perspective }\end{array}$ & \\
\hline & Data processing through local operators & \multirow{7}{*}{ Data Governance } \\
\hline & Need to simplify and process the extensive data & \\
\hline & Difficulty in data separation in process level & \\
\hline & Need to simplify and process the extensive data & \\
\hline & Data variation needs to manage & \\
\hline & Data governance & \\
\hline & $\begin{array}{l}\text { Managing extensive amount of data stored in different } \\
\text { places }\end{array}$ & \\
\hline & Need to have access and manage data & Data Ownership \\
\hline & The case company needs high quality data & \multirow{3}{*}{ Data Quality } \\
\hline & The case company needs reliable data & \\
\hline & The case company needs real time data & \\
\hline & The case company needs to access to 3 rd party data & External Data Access \\
\hline & $\begin{array}{l}\text { The case company is in search of extract value from } \\
\text { (underutilized)data }\end{array}$ & \multirow{5}{*}{ Extracting value from data } \\
\hline & $\begin{array}{l}\text { The case company is in search of fill the gap of production } \\
\text { logistic }\end{array}$ & \\
\hline & Analyzing data demand & \\
\hline & $\begin{array}{l}\text { Need to harmonize and managing these coming together in } \\
\text { the best possible way }\end{array}$ & \\
\hline & Need to iterative analyses and process optimization & \\
\hline & Importance of reliable local connection & \multirow{7}{*}{$\begin{array}{l}\text { High quality connection \& } \\
\text { content specific services }\end{array}$} \\
\hline & Needs for connectivity and data ownership requirements & \\
\hline & $\begin{array}{l}\text { The case company needs cloud-based connectivity to } \\
\text { update systems }\end{array}$ & \\
\hline & Automation requirements & \\
\hline & $\begin{array}{l}\text { The case company requires reliable traceability of } \\
\text { components in manufacturing line }\end{array}$ & \\
\hline & $\begin{array}{l}\text { The case company needs to prevent failures through } \\
\text { inventory tracking }\end{array}$ & \\
\hline & Local specifi demand, traceability & \\
\hline & $\begin{array}{l}\text { There is restriction in data access to keep system integrated } \\
\text { and safe }\end{array}$ & \multirow{2}{*}{ Internal Data Access } \\
\hline & $\begin{array}{l}\text { The case company don't have access to Surface Mount } \\
\text { Device line data concerning digital twin }\end{array}$ & \\
\hline & Real time and location specific data demand & \multirow{2}{*}{$\begin{array}{l}\text { Spatial/tailored content } \\
\text { requirements }\end{array}$} \\
\hline & The case company needs to manage private networks & \\
\hline
\end{tabular}

Figure A2. Content-related needs.

\begin{tabular}{|c|c|c|}
\hline $4 \mathrm{C} \mathrm{BMs}$ & First-order concept & Second-order theme \\
\hline \multirow{13}{*}{ 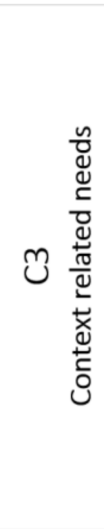 } & Importance of supply change improvement & \multirow{2}{*}{$\begin{array}{l}\text { Communication \& Data } \\
\text { Exchange/Sharing }\end{array}$} \\
\hline & Digitl twin in logestic & \\
\hline & $\begin{array}{l}\text { Surface Mount Device process is automated, so need } \\
\text { reliable on time data }\end{array}$ & Data quality \\
\hline & $\begin{array}{l}\text { Connect all the equipment wireless to central system in } \\
\text { future factories }\end{array}$ & Extracting value from data \\
\hline & External cloud for remote controlling & Extracting value from data \\
\hline & loT of wi-fi devices need wireless network & \multirow{8}{*}{$\begin{array}{l}\text { High quality connection \& } \\
\text { content specific services }\end{array}$} \\
\hline & Traffic handling in Oulu (need to replace with wireless) & \\
\hline & Controling lots of switches & \\
\hline & loT use cases connection wireless requirements & \\
\hline & Different components/players in subfloor layer & \\
\hline & Mobile connection requirements & \\
\hline & Automation requirements & \\
\hline & $\begin{array}{l}\text { Connected factory through wireless network requirement } \\
\text { provide by service providers }\end{array}$ & \\
\hline
\end{tabular}

Figure A3. Context-related needs. 


\begin{tabular}{|c|c|c|}
\hline 4C BMs & First-order concept & Second-order theme \\
\hline \multirow{7}{*}{ 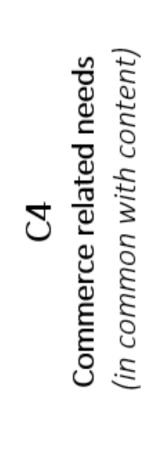 } & Need to have access and manage data & Data Ownership \\
\hline & The case company needs reliable data & Data Quality \\
\hline & The case company needs to access to 3 rd party data & External Data Access \\
\hline & $\begin{array}{l}\text { The case company is in search of extract value from } \\
\text { (underutilized)data }\end{array}$ & \multirow{2}{*}{ Extracting value from data } \\
\hline & $\begin{array}{l}\text { The case company is in search of fill the gap of } \\
\text { production logistic }\end{array}$ & \\
\hline & $\begin{array}{l}\text { There is restriction in data access to keep system } \\
\text { integrated and safe }\end{array}$ & Internal Data Access \\
\hline & $\begin{array}{l}\text { Need to save data locally through selected service } \\
\text { provider }\end{array}$ & $\begin{array}{l}\text { spatial/tailored content } \\
\text { requirements }\end{array}$ \\
\hline
\end{tabular}

Figure A4. Commerce-related needs.

\section{Appendix B. Data Structure of Future Factory's Resources Based on 4C}

\begin{tabular}{|c|c|c|}
\hline 4C BMs & First-order concept & Second-order theme \\
\hline \multirow{25}{*}{ 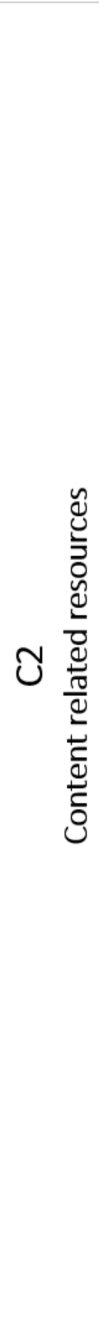 } & $\begin{array}{l}\text { Communication between the case company and machine } \\
\text { providores from data sharing perspective }\end{array}$ & \multirow{8}{*}{$\begin{array}{l}\text { Communication and data } \\
\text { exchange }\end{array}$} \\
\hline & Data access & \\
\hline & Geographically separate locations are connected & \\
\hline & Information from customers about product & \\
\hline & $\begin{array}{l}\text { The case company has data that willing to share to enhance } \\
\text { efficiency }\end{array}$ & \\
\hline & The case company willingness to share data & \\
\hline & The case company's willingness to sharing data is increasing & \\
\hline & $\begin{array}{l}\text { Middle ware which can simplify data flow between different } \\
\text { systems }\end{array}$ & \\
\hline & $\begin{array}{l}\text { In digital twin project, the case company has adequate } \\
\text { reporting system for different operators (but there are } \\
\text { difficulties in processing as mentioned in needs) }\end{array}$ & \multirow{3}{*}{ Data governance } \\
\hline & The case company utilize data to enhance processes & \\
\hline & $\begin{array}{l}\text { Middle ware which can simplify data flow between different } \\
\text { systems }\end{array}$ & \\
\hline & Factory has extensive amount of data & Data ownership \\
\hline & EMS customers information & \multirow{5}{*}{ External Data access } \\
\hline & $\begin{array}{l}\text { Sensor providores has their own method to collect and } \\
\text { provide data }\end{array}$ & \\
\hline & $\begin{array}{l}\text { The case company has ability to collect data from } \\
\text { subcontractors }\end{array}$ & \\
\hline & Access to big data in industry by EMS & \\
\hline & Available data in EMS & \\
\hline & Extensive amount of data exists & \multirow{3}{*}{ Extracting value from data } \\
\hline & Ability to turn data to more usable & \\
\hline & The case company has visual data base & \\
\hline & $\begin{array}{l}\text { The case company become more and more integrated/high } \\
\text { speed reconfiguring manufacturing line }\end{array}$ & Integration requirements \\
\hline & $\begin{array}{l}\text { Production manager is owner/has access to generated data } \\
\text { by machine in line }\end{array}$ & \multirow{2}{*}{ Internal Data access } \\
\hline & $\begin{array}{l}\text { Extensive data generated from connected machines in } \\
\text { automation line }\end{array}$ & \\
\hline & Different components/players in second floor layer & $\begin{array}{l}\text { High quality connection and } \\
\text { content specific services }\end{array}$ \\
\hline & $\begin{array}{l}\text { Fully virtualized network by local operators instead of } \\
\text { network slicing }\end{array}$ & Value co-creatin \\
\hline
\end{tabular}

Figure A5. Content-related resources. 


\begin{tabular}{|c|c|c|}
\hline 4C BMs & First-order concept & Second-order theme \\
\hline \multirow{3}{*}{ 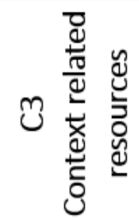 } & $\begin{array}{l}\text { Tracking/Connection data is available in testing area for } \\
\text { digital twin }\end{array}$ & $\begin{array}{l}\text { Communication and data } \\
\text { exchange }\end{array}$ \\
\hline & Nokia in search of new ideas & Extracting value from data \\
\hline & Extensive amount of indoor positioning devices & Internal Data access \\
\hline
\end{tabular}

Figure A6. Context-related resources.

\section{References}

1. Davies, R. Industry 4.0: Digitalisation for Productivity and Growth. European Parliamentary Research Service (EPRS), PE 568.337. 2015. Available online: http:/ / www.innovation4.cn/library/r14872 (accessed on 1 December 2021).

2. Putilo, N.V.; Volkova, N.S.; Antonova, N.V. Robotization in the Area of Labor and Employment: On the Verge of the Fourth Industrial Revolution. In Artificial Intelligence: Anthropogenic Nature vs. Social Origin; Popkova, E.G., Sergi, B.S., Eds.; Springer International Publishing: Cham, Switzerland, 2020; Volume 1100, pp. 60-75. [CrossRef]

3. Gong, Y.; Zhang, L.; Liu, R.P.; Yu, K.; Srivastava, G. Nonlinear MIMO for Industrial Internet of Things in Cyber-Physical Systems. IEEE Trans. Ind. Inf. 2021, 17, 5533-5541. [CrossRef]

4. Helmold, M.; Terry, B. Industry 4.0 and Artificial Intelligence (AI). In Operations and Supply Management 4.0; Springer International Publishing: Cham, Switzerland, 2021; pp. 77-83. [CrossRef]

5. Reis, M.S.; Gao, F. Special Issue "Advanced Process Monitoring for Industry 4.0". Processes 2021, 9, 1432. [CrossRef]

6. Lee, J.; Bagheri, B.; Kao, H.-A. A Cyber-Physical Systems architecture for Industry 4.0-based manufacturing systems. Manuf. Lett. 2015, 3, 18-23. [CrossRef]

7. Hermann, M.; Pentek, T.; Otto, B. Design Principles for Industrie 4.0 Scenarios. In Proceedings of the 201649 th Hawaii International Conference on System Sciences (HICSS), Koloa, HI, USA, 5-8 January 2016; pp. 3928-3937. [CrossRef]

8. Pujol, F.; Elayoubi, S.E.; Markendahl, J.; Salahaldin, L. Mobile Telecommunications Ecosystem Evolutions with 5G. Commun. Strateg. 2016, 102, 109159.

9. Bernold, H.T.; Steiger, M.; Wilms, M.; Bock, W.; Schicht, R. A Playbook for Accelerating 5G in Europe. 2018. Available online: https:/ / www.bcg.com/publications/2018/playbook-accelerating-5g-europe (accessed on 3 December 2021).

10. Fuentes, M.; Carcel, J.L.; Dietrich, C.; Yu, L.; Garro, E.; Pauli, V.; Lazarakis, F.I.; Grondalen, O.; Bulakci, O.; Yu, J.; et al. 5G New Radio Evaluation Against IMT-2020 Key Performance Indicators. IEEE Access 2020, 8, 110880-110896. [CrossRef]

11. 5G-PPP. 5G Empowering Vertical Industries. The 5G Infrastructure Public Private Partnership, Brussels. 2016. Available online: https://5g-ppp.eu/wp-content/uploads/2016/02/BROCHURE_5PPP_BAT2_PL.pdf (accessed on 10 October 2021).

12. Matinmikko, M.; Latva-Aho, M.; Ahokangas, P.; Seppänen, V. On regulations for 5G: Micro licensing for locally operated networks. Telecommun. Policy 2018, 42, 622-635. [CrossRef]

13. Matinmikko, M.; Latva-Aho, M.; Ahokangas, P.; Yrjölä, S.; Koivumäki, T. Micro Operators to Boost Local Service Delivery in 5G. Wirel. Pers. Commun. 2017, 95, 69-82. [CrossRef]

14. Ahokangas, P.; Moqaddamerad, S.; Matinmikko, M.; Atkova, I.; Gomes, J.; Iivari, M. Future micro operators' business models in 5G. Bus. Manag. Rev. 2016, 7, 143-149. [CrossRef]

15. Berthelsen, E. A New Agenda Item for Enterprise Executives: Enterprise IoT. ThingWorx, White Paper. 2015. Available online: https:/ / www.smartindustry.com/assets/Uploads/SI-WP-PTC-New-Agenda-Part-1.pdf (accessed on 11 October 2021).

16. Yrjola, S.; Ahokangas, P.; Matinmikko-Blue, M. Novel Context and Platform Driven Business Models via 5G Networks. In Proceedings of the 2018 IEEE 29th Annual International Symposium on Personal, Indoor and Mobile Radio Communications (PIMRC), Bologna, Italy, 9-12 September 2018; pp. 1-7. [CrossRef]

17. Ahokangas, P.; Matinmikko-Blue, M.; Yrjölä, S.; Hämmäinen, H. Platform configurations for local and private 5G networks in complex industrial multi-stakeholder ecosystems. Telecommun. Policy 2021, 45, 102128. [CrossRef]

18. Chochliouros, I.P.; Kostopoulos, A.; Spiliopoulou, A.S.; Dardamanis, A.; Neokosmidis, I.; Rokkas, T.; Goratti, L. Business and market perspectives in 5G networks. In Proceedings of the 2017 Internet of Things Business Models, Users, and Networks, Copenhagen, Denmark, 23-24 November 2017; pp. 1-6. [CrossRef]

19. Lourenço, J.; Almeida, F. The Impact of Emergent Technologies in the Evolutionary Path for M-Commerce. Research Anthology on E-Commerce Adoption, Models, and Applications for Modern Business. 2021. Available online: https: / / www.igi-global.com/chapter/the-impact-of-emergent-technologies-in-the-evolutionary-path-for-m-commerce/www.igiglobal.com/chapter/the-impact-of-emergent-technologies-in-the-evolutionary-path-for-m-commerce/281537 (accessed on 2 December 2021).

20. Soós, G.; Ficzere, D.; Seres, T.; Veress, S.; Németh, I. Business opportunities and evaluation of non-public 5G cellular networks-A survey. Infocommun. J. 2020, 12, 31-38. [CrossRef]

21. Ahokangas, P.; Matinmikko-Blue, M.; Yrjola, S.; Seppanen, V.; Hammainen, H.; Jurva, R.; Latva-Aho, M. Business Models for Local 5G Micro Operators. IEEE Trans. Cogn. Commun. Netw. 2019, 5, 730-740. [CrossRef] 
22. Weerasinghe, N.; Hewa, T.; Liyanage, M.; Kanhere, S.S.; Ylianttila, M. A Novel Blockchain-as-a-Service (BaaS) Platform for Local 5G Operators. IEEE Open J. Commun. Soc. 2021, 2, 575-601. [CrossRef]

23. Walia, J.S.; Hammainen, H.; Matinmikko, M. 5G Micro-operators for the future campus: A techno-economic study. In Proceedings of the 2017 Internet of Things Business Models, Users, and Networks, Copenhagen, Denmark, 23-24 November 2017; pp. 1-8. [CrossRef]

24. Siriwardhana, Y.; Porambage, P.; Liyanage, M.; Walia, J.S.; Matinmikko-Blue, M.; Ylianttila, M. Micro-Operator driven Local 5G Network Architecture for Industrial Internet. In Proceedings of the 2019 IEEE Wireless Communications and Networking Conference (WCNC), Marrakesh, Morocco, 15-18 April 2019; pp. 1-8. [CrossRef]

25. Li, X.; Guimaraes, C.; Landi, G.; Brenes, J.; Mangues-Bafalluy, J.; Baranda, J.; Corujo, D.; Cunha, V.; Fonseca, J.; Alegria, J.; et al Multi-Domain Solutions for the Deployment of Private 5G Networks. IEEE Access 2021, 9, 106865-106884. [CrossRef]

26. Matinmikko-Blue, M.; Yrjölä, S.; Ahokangas, P.; Hämmäinen, H. Analysis of 5G Spectrum Awarding Decisions: How Do Different Countries Consider Emerging Local 5G Networks? 2021. Available online: https://www.econstor.eu/handle/10419/238039 (accessed on 2 December 2021).

27. Amit, R.; Han, X. Value Creation through Novel Resource Configurations in a Digitally Enabled World: Novel Resource Configurations in a Digitally Enabled World. Strat. Entrep. J. 2017, 11, 228-242. [CrossRef]

28. Wirtz, B.W.; Schilke, O.; Ullrich, S. Strategic Development of Business Models. Long Range Plan. 2010, 43, 272-290. [CrossRef]

29. Yrjölä, S.; Matinmikko, M.; Ahokangas, P.; Mustonen, M. Licenced shared access to spectrum. In Spectrum Sharing in Wireless Networks: Fairness, Efficiency, and Security; Matyjas, J.D., Kumar, S., Hu, F., Eds.; CRC Press: Boca Raton, FL, USA, 2016; pp. 139-157.

30. Khan, I.S.; Ahmad, M.O.; Majava, J. Industry 4.0 and sustainable development: A systematic mapping of triple bottom line, Circular Economy and Sustainable Business Models perspectives. J. Clean. Prod. 2021, 297, 126655. [CrossRef]

31. Burmeister, C.; Luettgens, D.; Piller, F.T. Business Model Innovation for Industrie 4.0: Why the 'Industrial Internet' Mandates a New Perspective. SSRN J. 2015, 70, 124-152. [CrossRef]

32. Müller, J.M.; Däschle, S. Business Model Innovation of Industry 4.0 Solution Providers Towards Customer Process Innovation. Processes 2018, 6, 260. [CrossRef]

33. Frost \& Sullivan. Technology Innovations Impacting Future of Industrial Automation (Technical Insights); Frost \& Sullivan: San Antonio, TX, USA, 2015. Available online: https:/ / store.frost.com/technology-innovations-impacting-future-of-industrial-automationtechnical-insights.html? (accessed on 10 November 2021).

34. Knieps, G.; Bauer, J.M. Internet of things and the economics of 5G-based local industrial networks. Telecommun. Policy 2021, 102261. [CrossRef]

35. Peraković, D.; Periša, M.; Zorić, P.; Cvitić, I. Development and Implementation Possibilities of 5G in Industry 4.0. In Advances in Design, Simulation and Manufacturing III; Ivanov, V., Trojanowska, J., Pavlenko, I., Zajac, J., Peraković, D., Eds.; Springer International Publishing: Cham, Switzerland, 2020; pp. 166-175. [CrossRef]

36. Jovović, I.; Husnjak, S.; Forenbacher, I.; Maček, S. Innovative Application of 5G and Blockchain Technology in Industry 4.0. EAI Endorsed Trans. Ind. Netw. Intell. Syst. 2019, 6, 157122. [CrossRef]

37. Şimşek, T.; Öner, M.A.; Kunday, Ö.; Olcay, G.A. A journey towards a digital platform business model: A case study in a global tech-company. Technol. Forecast. Soc. Chang. 2021, 121372. [CrossRef]

38. Kandiah, G.; Gossain, S. Reinventing value: The new business ecosystem. Strat. Leadersh. 1998, 26, 28-33. [CrossRef]

39. Rong, K.; Hu, G.; Lin, Y.; Shi, Y.; Guo, L. Understanding business ecosystem using a 6C framework in Internet-of-Things-based sectors. Int. J. Prod. Econ. 2015, 159, 41-55. [CrossRef]

40. Teece, D.J. Business Models, Business Strategy and Innovation. Long Range Plan. 2010, 43, 172-194. [CrossRef]

41. Cantwell, J.A. Blurred Boundaries between Firms, and New Boundaries within (Large Multinational) Firms: The Impact of Decentralized Networks for Innovation. Seoul J. Econ. 2013, 26, 1-32.

42. Iivari, M. Exploring Business Models in Ecosystemic Contexts. Ph.D. Thesis, University of Oulu, Oulu, Finland, 2016. Available online: http:/ /jultika.oulu.fi/Record/isbn978-952-62-1240-1 (accessed on 20 September 2021).

43. Amit, R.; Zott, C. Crafting Business Architecture: The Antecedents of Business Model Design: Antecedents of Business Model Design. Strat. Entrep. J. 2015, 9, 331-350. [CrossRef]

44. Casadesus-Masanell, R.; Ricart, J.E. Competitiveness: Business model reconfiguration for innovation and internationalization. Manag. Res. J. Iberoam. Acad. Manag. 2010, 8, 123-149. [CrossRef]

45. Johnson, M.W.; Christensen, C.M.; Kagermann, H. Reinventing Your Business Model. No. December. 2008. Available online: https:/ /hbr.org/2008/12/reinventing-your-business-model (accessed on 18 October 2021).

46. Zott, C.; Amit, R. Business Model Design: An Activity System Perspective. Long Range Plan. 2010, 43, 216-226. [CrossRef]

47. Chesbrough, H.W.; Appleyard, M.M. Open Innovation and Strategy. Calif. Manag. Rev. 2007, 50, 57-76. [CrossRef]

48. Zott, C.; Amit, R. Business Model Design and the Performance of Entrepreneurial Firms. Organ. Sci. 2007, 18, 181-199. [CrossRef]

49. Osterwalder, A. The Business Model Ontology a Proposition in a Design Science Approach. Ph.D. Dissertation, University of Lausanne, Lausanne, Switzerland, 2004. Available online: https:/ / www.patrinum.ch/record/15985 (accessed on 10 November 2021).

50. Chesbrough, H. The role of the business model in capturing value from innovation: Evidence from Xerox Corporation's technology spin-off companies. Ind. Corp. Chang. 2002, 11, 529-555. [CrossRef]

51. Afuah, A. Business Model Innovation: Concepts, Analysis, and Cases; Routledge: Oxfordshire, UK, 2014. 
52. Boillat, T.; Legner, C. From On-Premise Software to Cloud Services: The Impact of Cloud Computing on Enterprise Software Vendors' Business Models. J. Theor. Appl. Electron. Commer. Res. 2013, 8, 7-8. [CrossRef]

53. Ahokangas, P.; Juntunen, M.; Myllykoski, J. Cloud Computing and Transformation of International E-Business Models. In $A$ Focused Issue on Building New Competences in Dynamic Environments; Emerald Group Publishing Limited: Bingley, UK, 2014; Volume 7, pp. 3-28. [CrossRef]

54. Stabell, C.B.; Fjeldstad, Ø.D. Configuring value for competitive advantage: On chains, shops, and networks. Strat. Mgmt. J. 1998, 19, 413-437. [CrossRef]

55. Fjeldstad, Ø.D.; Snow, C.C. Business models and organization design. Long Range Plan. 2018, 51, 32-39. [CrossRef]

56. Casey, T.; Smura, T.; Sorri, A. Value Network Configurations in wireless local area access. In Proceedings of the 20109 th Conference of Telecommunication, Media and Internet, Ghent, Belgium, 7-9 June 2010; pp. 1-9. [CrossRef]

57. Walia, J. Techno-Economic Analysis of 5G Local Area Access in Industrial Machine-to-Machine Communications. Master's Thesis, Aalto University, Helsinki, Finland, 2017. Available online: http:/ /urn.fi/URN:NBN:fi:aalto-201702242554 (accessed on 10 November 2021).

58. Bell, E.; Bryman, A.; Harley, B. Business Research Methods, 5th ed.; Oxford University Press: Oxford, UK, 2018.

59. Myers, M.D. Qualitative Research in Business and Management, 3rd ed.; SAGE Publications: Thousand Oaks, CA, USA, 2019.

60. Wilson, J. Essentials of Business Research: A Guide to Doing Your Research Project; SAGE Publications Ltd.: Thousand Oaks, CA, USA, 2010.

61. Gioia, D.A.; Corley, K.G.; Hamilton, A.L. Seeking Qualitative Rigor in Inductive Research: Notes on the Gioia Methodology. Organ. Res. Methods 2013, 16, 15-31. [CrossRef]

62. Krueger, R.A. Focus Groups: A Practical Guide for Applied Research; SAGE Publications: Thousand Oaks, CA, USA, 2014.

63. Urciuoli, L.; Hintsa, J.; Ahokas, J. Drivers and barriers affecting usage of e-Customs-A global survey with customs administrations using multivariate analysis techniques. Gov. Inf. Q. 2013, 30, 473-485. [CrossRef]

64. Rahimi, H.; Zibaeenejad, A.; Safavi, A.A. A Novel IoT Architecture based on 5G-IoT and Next Generation Technologies. In Proceedings of the 2018 IEEE 9th Annual Information Technology, Electronics and Mobile Communication Conference (IEMCON), Vancouver, BC, Canada, 1-3 November 2018; pp. 81-88. [CrossRef]

65. Eisenmann, T.R.; Parker, J.; Alstyne, M.V. Opening platforms: How, when and why. In Platforms, Markets and Innovation; Gawer, A., Ed.; Edward Elgar Publishing: Cheltenham, UK, 2009; pp. 131-162.

66. Türkes, M.C.; Oncioiu, I.; Aslam, H.D.; Marin-Pantelescu, A.; Topor, D.I.; Căpușneanu, S. Drivers and Barriers in Using Industry 4.0: A Perspective of SMEs in Romania. Processes 2019, 7, 153. [CrossRef]

67. Jeannerat, H.; Theurillat, T. Old industrial spaces challenged by platformized value-capture 4.0. Reg. Stud. 2021, 55, 1738-1750. [CrossRef]

68. Walia, J.S.; Hämmäinen, H.; Kilkki, K.; Yrjölä, S. 5G network slicing strategies for a smart factory. Comput. Ind. 2019, 111, 108-120. [CrossRef]

69. Xu, Y.; Ahokangas, P.; Turunen, M.; Mäntymäki, M.; Heikkilä, J. Xu Platform-Based Business Models: Insights from an Emerging Ai-Enabled Smart Building Ecosystem. Electronics 2019, 8, 1150. [CrossRef]

70. Chehri, A.; Zimmermann, A. G Assisted Smart Manufacturing and Industrial Automation. In Advances in the Human Side of Service Engineering; Leitner, C., Ganz, W., Satterfield, D., Bassano, C., Eds.; Springer International Publishing: Cham, Switzerland, 2021; Volume 266, pp. 385-393. [CrossRef]

71. Slalmi, A.; Chaibi, H.; Saadane, R.; Chehri, A.; Jeon, G. 5G NB-IoT: Efficient network call admission control in cellular networks. Concurr. Comput. Pract. Exp. 2021, 33, 6047. [CrossRef] 